CLINICAL STUDY

\title{
Genetic analysis in young patients with sporadic pituitary macroadenomas: besides AIP don't forget MEN1 genetic analysis
}

Thomas Cuny ${ }^{1,20}$, Morgane Pertuit ${ }^{2}$, Mona Sahnoun-Fathallah ${ }^{3}$, Adrian Daly ${ }^{4}$, Gianluca Occhi ${ }^{5}$, Marie Françoise Odou ${ }^{6}$, Antoine Tabarin ${ }^{7}$, Marie Laure Nunes ${ }^{7}$, Brigitte Delemer ${ }^{8}$, Vincent Rohmer ${ }^{9}$, Rachel Desailloud $^{10}$, Véronique Kerlan ${ }^{11}$, Olivier Chabre ${ }^{12}$, Jean-Louis Sadoul ${ }^{13}$, Muriel Cogne ${ }^{14}$, Philippe Caron ${ }^{15}$, Christine Cortet-Rudelli ${ }^{16}$, Anne Lienhardt ${ }^{17}$, Isabelle Raingeard ${ }^{18}$, Anne-Marie Guedj ${ }^{19}$, Thierry Brue ${ }^{3}$, Albert Beckers ${ }^{4}$, Georges Weryha ${ }^{1}$, Alain Enjalbert ${ }^{2,20}$ and Anne Barlier ${ }^{2,20}$

${ }^{1}$ Department of Endocrinology, University Hospital of Nancy - Brabois, 54500 Vandoeuvre-les-Nancy, France, ${ }^{2}$ Laboratory of Molecular Biology, University Hospital of Marseille - APHM - La Conception, 13005 Marseille, France, ${ }^{3}$ Department of Endocrinology, Centre de Reference des Maladies Rares d'Origine Hypophysaire DEFHY, University Hospital of Marseille - APHM - La Timone, 13385 Marseille cedex 5, France, ${ }^{4}$ Department of Endocrinology, University Hospital of Liège, University of Liège, 4000 Liège, Belgium, ${ }^{5}$ Department of Medicine, University of Padova, Padova, Italy, ${ }^{6}$ Laboratory of Biochemistry and Molecular Biology, University Hospital of Lille, 59037 Lille, France, ${ }^{7}$ Department of Endocrinology, University Hospital of Bordeaux - Haut-Lévèque, 33604 Pessac Cedex, France, ${ }^{8}$ Department of Endocrinology, University Hospital of Reims - Robert Debré, 51092 Reims, France, ${ }^{9}$ Department of Endocrinology, University Hospital of Angers, 49933 Angers Cedex 9, France, ${ }^{10}$ Department of Endocrinology, University Hospital of Amiens - Hopital Sud, 80054 Amiens Cedex, France, ${ }^{11}$ Department of Endocrinology, University Hospital of Brest - Cavale Blanche, 29609 Brest Cedex, France, ${ }^{12}$ Department of Endocrinology, University Hospital of Grenoble - Albert Michallon, 38043 Grenoble, France, ${ }^{13}$ Department of Endocrinology, University Hospital of Nice - Hôpital l'Archet, 06200 Nice, France, ${ }^{14}$ Department of Endocrinology, University Hospital of Reunion Island, Saint Pierre, France, ${ }^{15}$ Department of Endocrinology, University Hospital of Toulouse - Hopital Larrey, 31059 Toulouse, France, ${ }^{16}$ Department of Endocrinology, University Hospital of Lille, 59037 Lille, France, ${ }^{17}$ Department of Paediatrics, University Hospital of Limoges, 87000 Limoges, France, ${ }^{18}$ Department of Endocrinology, University Hospital of Montpellier - Hôpital Lapeyronie, 34295 Montpellier cedex, France, ${ }^{19}$ Department of Endocrinology, University Hospital of Nimes, 30000 Nîmes, France and ${ }^{20}$ Laboratoire CRN2M, UMR 7286-CNRS, Faculté de Médecine Nord, Aix-Marseille University, 51 Boulevard Pierre Dramard, 13344 Marseille cedex 15, France

(Correspondence should be addressed to A Barlier at Laboratoire CRN2M, UMR 7286-CNRS, Faculté de Médecine, Nord Aix-Marseille University; Email: anne.barlier@univ-amu.fr)

\begin{abstract}
Context: Germline mutations in the aryl hydrocarbon receptor interacting protein gene (AIP) have been identified in young patients (age $\leq 30$ years old) with sporadic pituitary macroadenomas. Otherwise, there are few data concerning the prevalence of multiple endocrine neoplasia type 1 (MEN1) mutations in such a population.

Objective: We assessed the prevalence of both AIP and MEN1 genetic abnormalities (mutations and large gene deletions) in young patients (age $\leq 30$ years old) diagnosed with sporadic and isolated macroadenoma, without hypercalcemia and/or MEN1-associated lesions.

Design: The entire coding sequences of AIP and MEN1 were screened for mutations. In cases of negative sequencing screening, multiplex ligation-dependent probe amplification was performed for the detection of large genetic deletions.

Patients and settings: One hundred and seventy-four patients from endocrinology departments of 15 French University Hospital Centers were eligible for this study.

Results: Twenty-one out of $174(12 \%)$ patients had AIP $(n=15,8.6 \%)$ or MEN1 $(n=6,3.4 \%)$ mutations. In pediatric patients (age $\leq 18$ years old), AIP/MEN1 mutation frequency reached nearly $22 \%(n=10 / 46)$. AIPmut and MEN1mut were identified in $8 / 79(10.1 \%)$ and $1 / 79(1.2 \%)$ somatotropinoma patients respectively; they each accounted for 4/74 (5.4\%) prolactinoma (PRL) patients with mutations. Half of those patients $(n=3 / 6)$ with gigantism displayed mutations in AIP. Interestingly, 4/12 (33\%) patients with non-secreting adenomas bore either AIP or MEN1 mutations, whereas none of the eight corticotroph adenomas or the single thyrotropinoma case had mutations. No large gene deletions were observed in sequencing-negative patients.

Conclusion: Mutations in MEN1 can be of significance in young patients with sporadic isolated pituitary macroadenomas, particularly PRL, and together with AIP, we suggest genetic analysis of MEN1 in such a population.
\end{abstract}

European Journal of Endocrinology 168 533-541 


\section{Introduction}

Familial cases of pituitary adenomas (PA) represent up to $5 \%$ of all $\mathrm{PA}$, with $2.7 \%$ related to multiple endocrine neoplasia type 1 (MEN1) (1) and nearly $2.5 \%$ related to the clinical entity familial isolated pituitary adenomas (FIPA) (2). Together the two syndromes comprise the most common causes of hereditary conditions predisposing to PA (3). In 2006, Vierimaa et al. (4) identified mutations in the aryl hydrocarbon receptor interacting protein (AIP) gene in the familial setting of PA. In FIPA kindreds, AIP mutations occur in $15-20 \%$ of cases (5), whereas they occur at a very low frequency in sporadic cases, between 0 and $4 \%(6,7,8,9)$. Because patients mutated for AIP (AIPmut) have typically early onset disease and larger PA compared with controls (10), Tichomirowa et al. (11) performed AIP screening in young patients with isolated sporadic macroadenomas and identified that nearly $12 \%$ of patients had germline AIP mutations.

Mutations in the tumor suppressor gene MEN1 predispose to multiple endocrine and non-endocrine diseases including PA (12) that occur in $\sim 40 \%$ of MEN1 cases (13). Whereas hyperparathyroidism is frequently reported as the first manifestation of MEN1 syndrome, pituitary disease can be the first lesion diagnosed in about $15 \%$ of patients with mutations in MEN1 (MEN1mut) $(13,14)$. Nevertheless, unlike AIP, there is limited data concerning the prevalence of MEN1 mutations in the specific subset of young patients diagnosed with isolated macroadenomas without any other disease of the MEN1 spectrum.

Therefore, we conducted a prospective study of a large cohort of patients in France that had been diagnosed with sporadic macroadenomas between January 2007 and December 2011 to determine the prevalence of both AIP and MEN1 gene abnormalities (point mutations and large deletions). We enrolled only patients diagnosed before 30 years old.

\section{Materials and methods}

\section{Subjects}

This genetic screening was performed in 174 patients with sporadic pituitary macroadenoma (maximal diameter $\geq 10 \mathrm{~mm}$ on pituitary MRI), diagnosed before 30 years of age and without hypercalcemia (corrected for serum albumin). Patients were enrolled from endocrinology departments of 15 French University Hospital Centers. All subjects provided informed written consent for the genetic screening. A subgroup of 59 patients had previously undergone AIP studies as part of an international collaborative study (11).

There were $79(45.4 \%)$ subjects with somatotropinomas ( 49 males and 30 females, mean age at diagnosis $24.2 \pm 5.9$ years), 74 (42.5\%) with prolactinomas (PRL; 39 males and 35 females, mean age $20.3 \pm 5.2$ years),
$12(6.8 \%)$ with clinically non-functioning PA (NFPAs, six males and six females, mean age $20.7 \pm 6$ years), eight $(4.6 \%)$ with corticotroph adenomas (two males and six females, age $22 \pm 5.4$ years), and one female, aged 25 years, with a thyrotropinoma.

None of the subjects had a family history of MEN1 or FIPA. Family members of MEN1mut or AIPmut patients were contacted whenever possible and underwent genetic screening, followed by pituitary MRI and hormonal testing in case of positive genetic analysis.

\section{Genomic analysis of AIP and MEN1}

Genomic DNA from peripheral blood leukocytes was extracted and the coding exons and exon-intron boundaries of the AIP and MEN1 genes (NM_130799.2, NM_003977.2) were PCR amplified and screened by direct sequencing. Genomic DNA was also analyzed for large deletion in both genes by multiplex ligation-dependent probe (Salsa MLPA probemix P244-B1 AIP-MEN1, MRC-Holland, Amsterdam, The Netherlands). A $4.8 \mathrm{Mb}$ region (from 11q13 to 11q13.3) was analyzed using probes localized on the MEN1 gene (exon 11, 10, 5 to 2), SNX15, FAM89B, RELA, SART1, and BRMTS1 genes; AIP gene (exons 1-6); and CCND1 gene. The potential effect of each missense or silent variation on AIP or menin protein was evaluated in silico using a battery of tools: Polyphen2 (http://genetics.bwh.harvard.edu), UMDpredictor (15), and Alamut 2.2.0 software (including SpliceSiteFinder, MaxEntScan, MNSPLICE, GeneSplicer, Human Splicing finder, RESCUE-ESE).

\section{Haplotype analysis}

The AIP p.Gly117Alafs*39 mutation carriers were genotyped using 14 microsatellite markers surrounding both AIP and MEN1 genes, located at 64.3 and $67.0 \mathrm{Mb}$ respectively. Markers were PCR amplified from genomic DNA, separated on an ABI 3730XL DNA sequencer, and analyzed with Peak Scanner v1.0 software (Applied Biosystems). Genetic markers' primers sequences and amplification condition were reported elsewhere (16).

\section{Statistical analysis}

The Mann-Whitney $U$ test was used for statistical analysis. $P$ values below 0.05 were considered to denote statistical significance in this study. The mean age at diagnosis in each group of patients is referred to with S.D. (mean age \pm s.D.).

\section{Results}

\section{Genomic DNA AIP and MEN1 mutations among the study cohort}

AIP and MEN1 genetic analysis in the study cohort identified 21 patients bearing mutations (21/174, 
$12 \%)$. Fifteen had AIP (8.6\%) and six had MEN1 (3.4\%) mutations (Table 1). No large genetic deletion was observed in any case using MLPA. In the cohort, the mean age at diagnosis was significantly lower in AIPmut patients compared with MEN1mut and non-mutated groups (18.7 \pm 5 years (AIP) vs $22.2 \pm 7.6$ years (MEN1) and 22.7 \pm 5.7 years (non-mutated group) respectively, $P<0.05$ ).

In the pediatric population (i.e. age $\leq 18$ years at diagnostic, $n=46)$, ten patients $(21.7 \%$, patients $3-6-7$ 9-10-13-14-15-16-19) bore mutations (seven in AIP and three in MEN1). The pediatric population included 30 PRL $(65 \%), 11$ somatotropinomas $(24 \%)$, three NFPAs (6.5\%), and two ACTH-secreting adenomas $(4.5 \%)$. There were 28 females $(61 \%)$ and 18 males $(39 \%)$, and the high proportion of females observed is due to the macroprolactinoma subgroup. The age at diagnosis of patients with AIP or MEN1 mutations was similar to their non-mutated pediatric counterparts (mean age $14.7 \pm 2.8$ years for AIPmut group, 15.3 \pm 2.1 years for MEN1mut group, and $14.6 \pm 3.6$ years in non-mutated group, NS).

Overall, 11 different AIP variants were identified: seven of them led to a premature codon stop (Table 1), suggesting that they are deleterious. The variant p.Gly117Alafs*39 was found in five unrelated patients originating from two geographically close regions (two from Reunion, three from Comoros Islands, all of them are of African origin). To address the issue of a possible founder effect, we genotyped 14 microsatellite markers surrounding the AIP gene. Although the lack of information on pedigrees and allele frequencies do not consent to draw final conclusions, our data are strongly suggestive for a common ancestor at least for four out five subjects sharing a genomic region on chromosome 11 ranging from 4.4 to $7.5 \mathrm{Mb}$ (Table 2).

The four AIP remaining variants included two missense variants (p.Lys58Asn and p.Arg304Gln), previously reported as deleterious in the literature (11, 17 ), and two previously undescribed variants. The variant p.Leu 294Pro is localized on exon 6, in the third tetratricopeptide repeat (TPR) domain, known as a key domain for protein-protein interactions and scored as being likely to affect AIP protein on in silico analyses. The deletion of three bases (c. 735_737 del) in exon 5 induces the loss of glutamine 246 in the second TPR domain (18), therefore supporting a strong pathological role of this mutant.

Genetic screening of family members of affected mutation carriers was possible in three different families (overall 11 subjects tested) and was positive in three subjects, the mother (aged 45) and the maternal grand father (aged 80) of patient 11 (p.Lys58Asn) and the mother (aged 51) of patient 12 (p.Arg304Gln). In all these carriers, pituitary MRI was normal.

Among the six MEN1 variants identified in our cohort, three of them led to premature stop codons, suggesting a deleterious effect (Table 1). The intronic mutation (c.655-6C $>\mathrm{T}$ ) induces a deletion of exon 3 causing a frameshift and a premature stop codon 13 triplets further downstream (19). The two other variants included one missense mutation (p.Pro540Ser), already described but without demonstration of pathogenic effect in the original report (20), and one novel missense variant (p.Asp231His). In silico analysis showed a moderate to strong likelihood of a deleterious effect for these two variants (Table 1).

Genetic screening has been conducted in three family members (mother, father, and brother) of patient 16. The genetic analysis was positive in the asymptomatic father and allowed the diagnosis of asymptomatic primary hyperparathyroidism, hitherto unknown, with a normal pituitary MRI. The genetic screening of MEN1 has also been done in the mother of patient 15 and was negative.

\section{Analysis by phenotype}

Nine out of 79 (11.4\%) somatotropinoma patients had AIP (six males and two females) or MEN1 mutations (one male, Table 1). Three out of six patients with gigantism were identified with AIP mutations (two males and one female) (Table 1). Patient 7 , with the novel AIP missense variant p.Leu294Pro, was diagnosed at 10 years of age and was resistant to somatostatin analog therapy.

Eight out of 74 (10.8\%) PRL patients bore AIP (three males and one female) or MEN1 (two males and two females) mutations (Table 1). The new missense MEN1 mutant (p.Asp231His) was identified in a 29-year-old male, who was affected by an aggressive PRL that was resistant to dopamine agonist therapy.

Only 12 patients $(6.9 \%)$ from our whole cohort were affected by NFPAs. Four of them (33\%) were identified as having either AIP or MEN1 mutations (Table 1). The deletion of a glutamine (p.Glu246del) in AIP protein was found in a young male, aged 20, who had a macroadenoma with partial immunoreactivity for $\mathrm{GH}$ $(50 \%)$ but without any pituitary hormonal hypersecretion in vivo.

No mutation was identified in the eight patients diagnosed with corticotroph adenoma and in the female with a thyrotropinoma.

\section{Discussion}

Until 2006, mutations in the MEN1 gene were the main molecular abnormalities seen in cases of familial PA, particularly in association with other endocrine diseases. The implication of germline mutations in the AIP gene has since significantly extended the field of genetic analysis in apparent familial predisposition to PA (4).

While the data on AIP mutation status in the current study largely supports the emerging profile of the ideal 


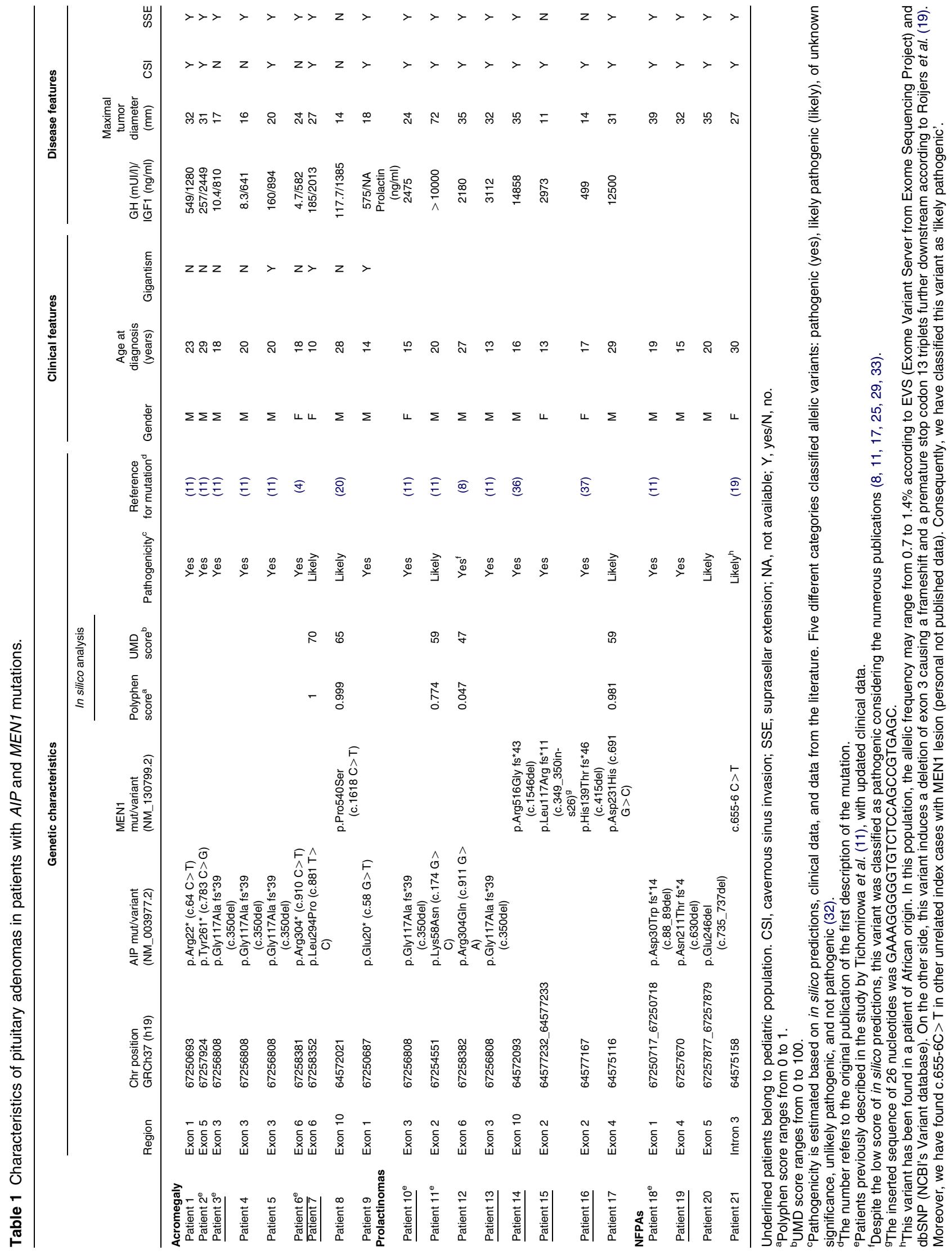


Table 2 Molecular markers on chromosome 11 and haplotype data of five AIP p.Gly117Alafs*39 mutation carriers, three originating from Comoros Islands $(\mathrm{C} 1, \mathrm{C} 2$ and $\mathrm{C} 3)$ and two from Reunion (R1, R2). Bold represents the more likely at-risk haplotype shared by at least two subjects.

\begin{tabular}{|c|c|c|c|c|c|c|c|c|c|c|c|}
\hline \multirow{3}{*}{$\begin{array}{l}\text { Marker } \\
\text { D11S4076 } \\
\text { m 11TETRA@61.73 }\end{array}$} & \multirow{2}{*}{$\begin{array}{c}\begin{array}{c}\text { Genomic } \\
\text { position }^{\mathrm{a}}\end{array} \\
61.1\end{array}$} & \multicolumn{2}{|c|}{ C1 } & \multicolumn{2}{|c|}{$\mathrm{C} 2$} & \multicolumn{2}{|c|}{ C3 } & \multicolumn{2}{|c|}{ R1 } & \multicolumn{2}{|c|}{$\mathbf{R 2}$} \\
\hline & & 154 & 156 & 154 & 154 & 154 & 154 & 154 & 152 & 152 & 156 \\
\hline & 61.7 & 356 & 352 & 356 & 348 & 348 & 352 & 356 & 344 & 348 & 348 \\
\hline CḦR11_64_AC_110 & 64.5 & 117 & 121 & 117 & 117 & 117 & 113 & 117 & 123 & 117 & 121 \\
\hline Chr11-64-TG-110 & 65.2 & 142 & 144 & 142 & 142 & 142 & 142 & 142 & 140 & 140 & 144 \\
\hline D11S913 & 65.9 & 116 & 120 & 116 & 116 & 116 & 124 & 116 & 118 & 116 & 120 \\
\hline AFMA190YD5 & 66.7 & 269 & 277 & 269 & 269 & 269 & 269 & 269 & 273 & 269 & 273 \\
\hline D11S1889 & 67.1 & 377 & 371 & 377 & 377 & 377 & 373 & 377 & 377 & 377 & 375 \\
\hline ACRO_CHR11_28 & 67.2 & 203 & 203 & 203 & 231 & 203 & 229 & 203 & 229 & 203 & 227 \\
\hline D11S987 & 67.6 & 104 & 106 & 104 & 100 & 104 & 106 & 104 & 100 & 106 & 106 \\
\hline D11S4113 & 68.9 & 284 & 286 & 284 & 290 & 284 & 264 & 284 & 294 & 284 & 264 \\
\hline D11S4095 & 69.2 & 115 & 125 & 115 & 125 & 121 & 127 & 115 & 119 & 115 & 125 \\
\hline D11S4136 & 69.6 & 129 & 135 & 129 & 129 & 129 & 131 & 129 & 121 & 129 & 131 \\
\hline D11S4162 & 70.6 & 180 & 178 & 180 & 178 & 180 & 180 & 176 & 182 & 176 & 178 \\
\hline D11S1314 & 72.0 & 346 & 336 & NA & NA & 346 & 338 & 344 & 348 & 344 & 340 \\
\hline
\end{tabular}

NA, not available.

${ }^{\mathrm{a} B a s e d}$ on the human NCBI36/hg18 genome assembly.

screening candidates, the major new finding relates to MEN1 screening in young sporadic pituitary macroadenoma patients. There are few data assessing the prevalence of MEN1 mutations in the specific case of isolated and sporadic macroadenoma. Stratakis et al. (21) reported one MEN1 mutation in a 11-year-old male with macroprolactinoma among six patients with isolated GH- or PRL-secreting adenoma. In our study, MEN1 mutations were identified in $3.4 \%$ of cases and this frequency reaches $6.5 \%$ in the pediatric population $(n=3 / 46)$. No large genomic deletion was identified among MEN1-sequencing-negative patients; such findings have been reported previously in 1\% of MEN1 families (22). In contrast to AIPmut patients, MEN1mut patients from our series had the same age at diagnosis as the population without mutation, in agreement with the data from Verges et al. (13) on micro- and macroadenomas. In invasive adenoma group from the study by Trouillas et al. (23), MEN1mut patients tended to be younger than their non-mutated counterparts. In the oncogenetic field, and particularly for MEN1 and hyperparthyroidism, it is well known that tumors arise earlier in mutated patients than in their non-mutated counterparts. In MEN1 pituitary tumors, data are missing to claim it. Consistent with the literature (13), PRL are over-represented in our MEN1mut patients (4/6, 66\% in our cohort). Consequently, our results suggest that MEN1 mutations should be strongly considered in the young sporadic pituitary macroprolactinoma population, as we found an equal frequency of AIP and MEN1 mutations in our cohort (Fig. 1).

In our cohort, only one MEN1mut patient (patient 15) has developed primary hyperparathyroidism to date. Moreover, this hyperparathyroidism was completely asymptomatic and diagnosed about 10 years after the first symptoms of pituitary tumor. In addition, one family member of MEN1 proband (patient 16) was subsequently diagnosed with occult hyperparathyroidism thanks to positive genetic screening. Therefore, the genetic screening performed in family members of MEN1mut patients could result in a contributive diagnosis and therapeutic intervention. This is in line with the high penetrance of the MEN1 syndrome estimated near $90 \%$ at the age of 50 years (12).

By definition, FIPA families are free of mutations in the MEN1 gene. While our results show that both AIP and MEN1 contributed to sporadic macroadenomas in young patients, we have not found that MEN1 mutations can lead to isolated PA in a familial setting. We still have not identified any MEN1 mutations in the unrelated patients from our FIPA cohort (personal communication). This might be the consequence of the high frequency and penetrance of hyperparathyroidism (24). Hyperparathyroidism should be actively searched in cases of family members with isolated PA to focus genetic analysis either on MEN1 or on AIP. Subsequently, MEN1 genetic screening may now not be necessary a priori before designating kindred with multiple related members with isolated PA as having FIPA (Fig. 1).

The prevalence of AIP mutations in patients with sporadic pituitary adenoma without considering the age at diagnosis is low, between $0-4 \%(6,9,25,26)$, including in those with sporadic macrodenoma (27). Strikingly, this frequency reaches $12 \%$ in young patients (age $\leq 30$ years) with sporadic macroadenoma (11), strongly supporting the idea that young patients should be the primary targets of genetic screening. Accordingly, our study identifies an overall mutation prevalence of AIP of $8.6 \%$ in a similarly selected population. Two studies on patients diagnosed before 40 years have previously reported an AIP mutation frequency 


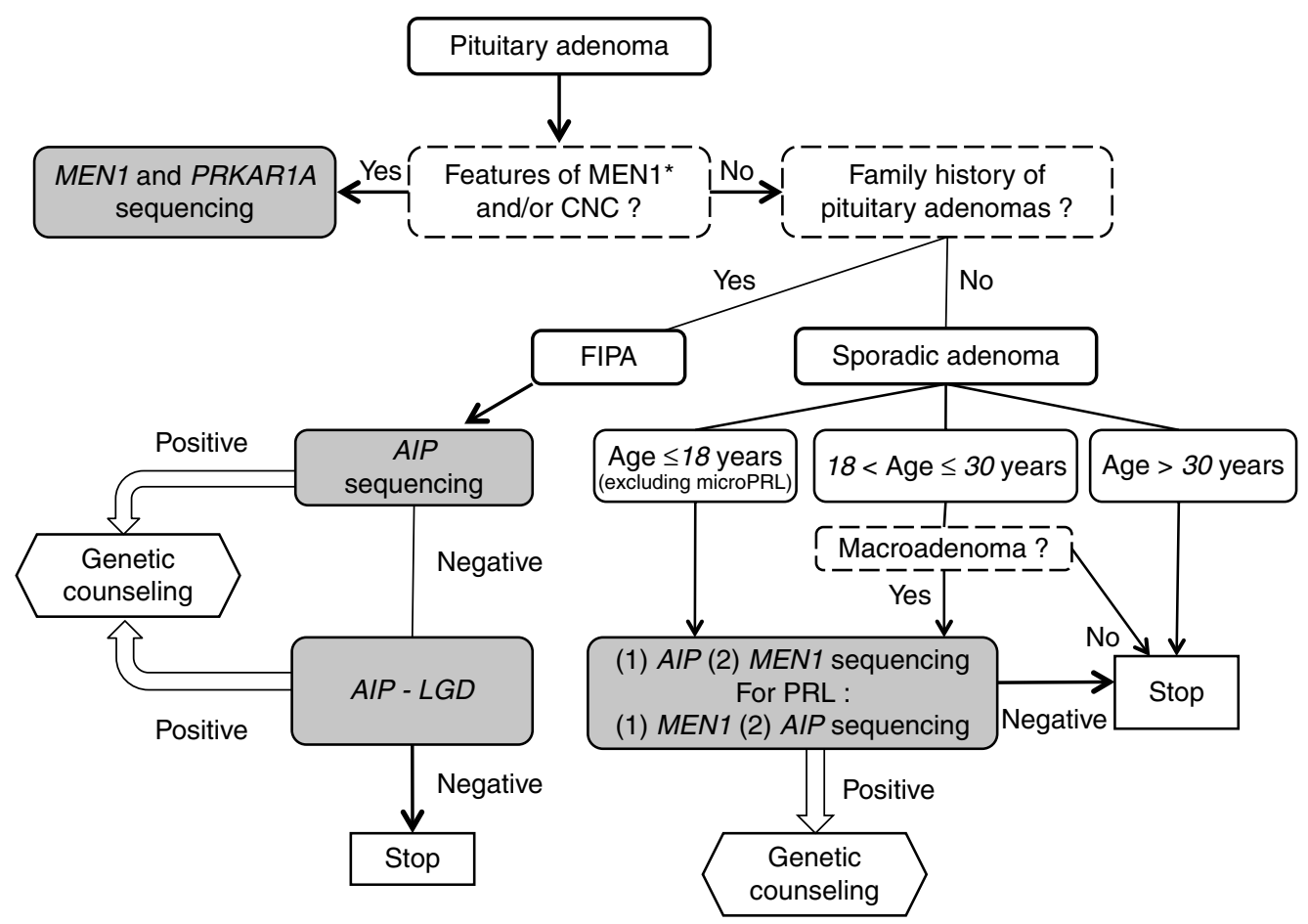

Figure 1 Suggested algorithm for $A I P$ and $M E N 1$ genetic screening in clinically relevant pituitary adenoma (PA). Adapted from references (34) and (35). *Hyperparathyroidism should be actively searched for in all patients with PA. In patients diagnosed before 30 years old with sporadic macroadenoma, we suggest to perform first $A I P$ and secondarily MEN1 genetic screening, except for PRL. In the pediatric arm, we proposed to perform AIP and MEN1 genetic screening in all cases, except for microprolactinomas considering the high frequency of this tumor in young females and even if data are missing to support this proposal. CDKN1B is not included in this algorithm because MEN4 is a very rare syndrome (33) and this algorithm focuses on routine genetic testing. McCune Albright is currently one of the syndromes that could be associated with PA, but it is not a hereditary syndrome, as the mutation of the locus GNAS is present as mosaicism. No activating mutation has been reported so far in humans at germinal level, probably because the germinal activating mutation is lethal for the embryo. This algorithm focuses exclusively on PA predisposition syndromes for which subsequent genetic analysis could be performed in the family members. AIP, aryl hydrocarbon receptor interacting protein; CNC, Carney complex; LGD, large gene deletion detection; MEN1, multiple endocrine neoplasia type 1; PRL, prolactinoma; PRKAR1A, regulatory R1A subunit of protein kinase A.

near $7 \%(7,8)$. This prevalence reaches $14.3 \%$ in patients with GH-secreting tumors diagnosed before 25 years old (28). All these data lead us to propose to limit the genetic screening to subjects younger than 30 years old (Fig. 1).

In our pediatric population, AIP mutation prevalence reaches nearly $15 \%$ and as high as $40 \%(n=4 / 10)$ in cases of acromegaly. In the literature, the frequency of AIP mutations in such populations varied from $2 \%$ $(1 / 36)(28)$ to $20-23 \%(11,25)$. Not only the age at diagnosis but also the size of the tumor is an important criterion that modifies the frequency of AIP mutation in isolated sporadic PA. The tumors from AIPmut patients in a FIPA cohort were overwhelmingly macroadenomas (10). However, among 74 children with Cushing's disease, one AIP mutation was found in a patient diagnosed at the age of 6 years with a $3 \times 4 \mathrm{~mm}$ ACTH-secreting adenoma (21). Subsequently, data are missing in the pediatric population to support the exclusion of children with microadenoma from the AIP genetic screening that we suggest in Fig. 1.
In our study, the majority of AIP mutations were found in somatotropinoma patients $(8 / 15$ mutated patients) as previously known (10). No mutation was found in corticotroph adenoma patients and in the single thyrotropinoma patient. However, AIP mutations have already been reported in several young patients with isolated sporadic corticotroph adenomas $(7,21)$, justifying AIP screening in such populations (Fig. 1). There is a variable penetrance of FIPA in AIPmut families with around $20-30 \%$ in the largest cohort studied (5, 29). Indeed, in our study, the positive genetic screening in the three family members was not accompanied by the identification of any PA on MRI. In five AIPmut carriers from the study of Cazabat $e t$ al. (7), no adenoma was identified by MRI, and of the AIPmut carriers $(n=2 / 21)$ from the study conducted by Tichomirowa et al. (11), two family members (not included in the current study) were diagnosed with a microadenoma and without associated hormonal oversecretion. Whether there are specific AIP mutants associated with higher penetrance of the disease 
remains unknown. On the one hand, these observations are in agreement with the low penetrance of the FIPA syndrome; on the other hand, it asks the question of substantial benefits of AIP screening for asymptomatic family members. A long prospective study is clearly required to assess the impact of AIP screening in family members of AIPmut patients in order to clarify the natural history of asymptomatic AIPmut carriers.

In mutation-negative patients, we did not identify any large genomic deletion of AIP by MLPA in agreement with three other previous studies $(6,7,11)$. This molecular abnormality could account for $9.5 \%$ of AIPnegative FIPA kindreds (30), and among 64 unrelated patients from a FIPA cohort of our laboratory, we identified one family member of homogenous FIPA with acromegaly, with large genomic deletion of AIP in exon 1 (A Barlier, personal communication). Considering the cost and the difficulties of this analysis, MLPA analysis should be considered primarily in cases of FIPA that are first shown to be negative on AIP sequencing.

Finally, our study identified an overall mutation prevalence of $12 \%$ for AIP and MEN1. Surprisingly, this frequency reaches 33\% for patients diagnosed with NFPA $(n=4 / 12)$. However, among the four patients, one of them (AIP mutated) was a silent somatotroph macroadenoma, whereas the remaining three others were nonreactive on immunostaining experiments. Excluding the silent somatotroph case, the mutation frequency of AIP becomes $20 \%(2 / 10)$, still higher than that observed in the study conducted by Tichomirowa et al. $(6.3 \%,(11))$. NFPA are very rare tumors in the population aged under 30 years old. Therefore, further studies are needed to clarify the mutation prevalence in young NFPA patients.

Although the MEN1 mutation prevalence was only to $3.4 \%$ in our series, taking into account the high penetrance of MEN1 syndrome, together with the possibility of up to $10 \%$ of de novo mutations (31) and the strong impact of MEN1 mutations in terms of genetic counseling and therapeutic management, we suggest to include not only AIP but also MEN1 genetic analysis in young patients with sporadic PA (Fig. 1). Nevertheless, in the current guidelines for MEN1 management, the genetic analysis of MEN1 is not specifically recommended in this kind of population (24). But until now, there were no data on the prevalence of MEN1 mutations in young patients with sporadic and isolated PA, particularly macroprolactinomas. Further investigations are required before including MEN1 genetic screening in clinical practice in such a population. Even if the phenotypes induced by a point mutation or a large deletion of the gene are not different $(22,30)$, the latter group might be associated with increased penetrance (30). Therefore, according to our results and those of the literature $(7,11)$, seeking large AIP and/or MEN1 deletions seems unjustified as a routine measure in cases of isolated sporadic PA even in young patients (Fig. 1).

\section{Declaration of interest}

The authors declare that there is no conflict of interest that could be perceived as prejudicing the impartiality of the research reported.

\section{Funding}

This work was supported by the Association pour le Développement des Recherches Biologiques et Médicales au Centre Hospitalier Régional de Marseille (ADEREM), Oncogenetic Network of the French Ministry of Health, CNRS.

\section{Acknowledgements}

The authors are grateful for the families providing samples and to the referring doctors including Dr Teynie, Dr Ronci-Chaix, Dr Carlier (CHU Bordeaux, France), Dr Morange, Dr Castinetti, Dr Albarel, Dr Simonin, Dr Grangeot (CHU Marseille, France), Dr Sonnet (CHU Brest, France), Pr Gaillard (CHU Reims, France), Dr Langbour-Remy, Pr Leheup (CHR Metz, CHU Nancy, France), Dr Vezzosi (CHU Toulouse, France), Dr Hieronimus, Dr Brucker-Davis (CHU Nice, France). The authors are grateful to Dr Beroud (CHU Marseille, France) for his help in in silico analysis and Dr Bernard (CHU Marseille, France) for paternal test. They are grateful to Anne Carle, Chantal Bideau, Danièle Iniesta, and Sandrine Bosc for MEN1 and AIP genetic screening.

\section{References}

1 Scheithauer BW, Laws ER Jr, Kovacs K, Horvath E, Randall RV \& Carney JA. Pituitary adenomas of the multiple endocrine neoplasia type I syndrome. Seminars in Diagnostic Pathology 1987 $4205-211$.

2 Daly AF, Jaffrain-Rea ML, Ciccarelli A, Valdes-Socin H, Rohmer V, Tamburrano G, Borson-Chazot C, Estour B, Ciccarelli E, Brue T et al. Clinical characterization of familial isolated pituitary adenomas. Journal of Clinical Endocrinology and Metabolism 2006 91 3316-3323. (doi:10.1210/jc.2005-2671)

3 Beckers A \& Daly AF. The clinical, pathological, and genetic features of familial isolated pituitary adenomas. European Journal of Endocrinology 2007157 371-382. (doi:10.1530/EJE-07-0348)

4 Vierimaa O, Georgitsi M, Lehtonen R, Vahteristo P, Kokko A, Raitila A, Tuppurainen K, Ebeling TM, Salmela PI, Paschke R et al. Pituitary adenoma predisposition caused by germline mutations in the AIP gene. Science 2006312 1228-1230. (doi:10.1126/ science.1126100)

5 Daly AF, Vanbellinghen JF, Khoo SK, Jaffrain-Rea ML, Naves LA, Guitelman MA, Murat A, Emy P, Gimenez-Roqueplo AP, Tamburrano G et al. Aryl hydrocarbon receptor-interacting protein gene mutations in familial isolated pituitary adenomas: analysis in 73 families. Journal of Clinical Endocrinology and Metabolism 200792 1891-1896. (doi:10.1210/jc.2006-2513)

6 Barlier A, Vanbellinghen JF, Daly AF, Silvy M, Jaffrain-Rea ML, Trouillas J, Tamagno G, Cazabat L, Bours V, Brue T et al. Mutations in the aryl hydrocarbon receptor interacting protein gene are not highly prevalent among subjects with sporadic pituitary adenomas. Journal of Clinical Endocrinology and Metabolism 200792 1952-1955. (doi:10.1210/jc.2006-2702)

7 Cazabat L, Bouligand J, Salenave S, Bernier M, Gaillard S, Parker F, Young J, Guiochon-Mantel A \& Chanson P. Germline AIP mutations in apparently sporadic pituitary adenomas: prevalence in a prospective single-center cohort of 443 patients. Journal of Clinical Endocrinology and Metabolism 201297 E663-E670. (doi:10.1210/jc.2011-2291)

8 Georgitsi M, Raitila A, Karhu A, Tuppurainen K, Makinen MJ, Vierimaa O, Paschke R, Saeger W, van der Luijt RB, Sane T et al. Molecular diagnosis of pituitary adenoma predisposition caused by aryl hydrocarbon receptor-interacting protein gene mutations. PNAS 2007104 4101-4105. (doi:10.1073/pnas.0700004104) 
9 Yu R, Bonert V, Saporta I, Raffel LJ \& Melmed S. Aryl hydrocarbon receptor interacting protein variants in sporadic pituitary adenomas. Journal of Clinical Endocrinology and Metabolism 2006 91 5126-5129. (doi:10.1210/jc.2006-1731)

10 Daly AF, Tichomirowa MA, Petrossians P, Heliovaara E, JaffrainRea ML, Barlier A, Naves LA, Ebeling T, Karhu A, Raappana A et al. Clinical characteristics and therapeutic responses in patients with germ-line AIP mutations and pituitary adenomas: an international collaborative study. Journal of Clinical Endocrinology and Metabolism 201095 E373-E383. (doi:10.1210/jc.20092556)

11 Tichomirowa MA, Barlier A, Daly AF, Jaffrain-Rea ML, Ronchi C, Yaneva M, Urban JD, Petrossians P, Elenkova A, Tabarin A et al. High prevalence of AIP gene mutations following focused screening in young patients with sporadic pituitary macroadenomas. European Journal of Endocrinology $2011 \quad 165$ 509-515. (doi:10.1530/EJE-11-0304)

12 Brandi ML, Gagel RF, Angeli A, Bilezikian JP, Beck-Peccoz P, Bordi C, Conte-Devolx B, Falchetti A, Gheri RG, Libroia A et al. Guidelines for diagnosis and therapy of MEN type 1 and type 2 . Journal of Clinical Endocrinology and Metabolism $2001 \mathbf{8 6}$ 5658-5671. (doi:10.1210/jc.86.12.5658)

13 Verges B, Boureille F, Goudet P, Murat A, Beckers A, Sassolas G, Cougard P, Chambe B, Montvernay C \& Calender A. Pituitary disease in MEN type 1 (MEN1): data from the France-Belgium MEN1 multicenter study. Journal of Clinical Endocrinology and Metabolism 200287 457-465. (doi:10.1210/jc.87.2.457)

14 Syro LV, Scheithauer BW, Kovacs K, Toledo RA, Londono FJ, Ortiz LD, Rotondo F, Horvath E \& Uribe H. Pituitary tumors in patients with MEN1 syndrome. Clinics 201267 (Suppl 1) 43-48. (doi:10.6061/clinics/2012(Sup01)09)

15 Frederic MY, Lalande M, Boileau C, Hamroun D, Claustres M, Beroud C \& Collod-Beroud G. UMD-predictor, a new prediction tool for nucleotide substitution pathogenicity - application to four genes: FBN1, FBN2, TGFBR1, and TGFBR2. Human Mutation 200930 952-959. (doi:10.1002/humu.20970)

16 Occhi G, Jaffrain-Rea ML, Trivellin G, Albiger N, Ceccato F, De Menis E, Angelini M, Ferasin S, Beckers A, Mantero F et al. The R304X mutation of the aryl hydrocarbon receptor interacting protein gene in familial isolated pituitary adenomas: mutational hot-spot or founder effect? Journal of Endocrinological Investigation 201033 800-805.

17 Leontiou CA, Gueorguiev M, van der Spuy J, Quinton R, Lolli F, Hassan S, Chahal HS, Igreja SC, Jordan S, Rowe J et al. The role of the aryl hydrocarbon receptor-interacting protein gene in familial and sporadic pituitary adenomas. Journal of Clinical Endocrinology and Metabolism 200893 2390-2401. (doi:10.1210/jc.20072611)

18 Trivellin G \& Korbonits M. AIP and its interacting partners. Journal of Endocrinology 2011210 137-155. (doi:10.1530/JOE11-0054)

19 Roijers JF, de Wit MJ, van der Luijt RB, Ploos van Amstel HK, Hoppener JW \& Lips CJ. Criteria for mutation analysis in MEN 1-suspected patients: MEN 1 case-finding. European Journal of Clinical Investigation 200030 487-492. (doi:10.1046/j.13652362.2000.00664.x)

20 Crepin M, Escande F, Pigny P, Buisine MP, Calender A, Porchet N, Odou MF \& Groupe d'Etude des Neoplasies Endocriniennes Multiples L. Efficient mutation detection in MEN1 gene using a combination of single-strand conformation polymorphism (MDGA) and heteroduplex analysis. Electrophoresis $2003 \mathbf{2 4}$ 26-33. (doi:10.1002/elps.200390023)

21 Stratakis CA, Tichomirowa MA, Boikos S, Azevedo MF, Lodish M, Martari M, Verma S, Daly AF, Raygada M, Keil MF et al. The role of germline AIP, MEN1, PRKAR1A, CDKN1B and CDKN2C mutations in causing pituitary adenomas in a large cohort of children, adolescents, and patients with genetic syndromes. Clinical Genetics 201078 457-463. (doi:10.1111/j.1399-0004. 2010.01406.x)
22 Owens M, Ellard S \& Vaidya B. Analysis of gross deletions in the MEN1 gene in patients with multiple endocrine neoplasia type 1. Clinical Endocrinology 200868 350-354. (doi:10.1111/j.13652265.2007.03045.x)

23 Trouillas J, Labat-Moleur F, Sturm N, Kujas M, Heymann MF, Figarella-Branger D, Patey M, Mazucca M, Decullier E, Verges B et al. Pituitary tumors and hyperplasia in multiple endocrine neoplasia type 1 syndrome (MEN1): a case-control study in a series of 77 patients versus 2509 non-MEN1 patients. American Journal of Surgical Pathology 200832 534-543. (doi:10.1097/ PAS.0b013e31815ade45)

24 Thakker RV, Newey PJ, Walls GV, Bilezikian J, Dralle H, Ebeling PR, Melmed S, Sakurai A, Tonelli F \& Brandi ML. Clinical practice guidelines for multiple endocrine neoplasia type 1 (MEN1). Journal of Clinical Endocrinology and Metabolism 201297 2990-3011. (doi:10.1210/jc.2012-1230)

25 Cazabat L, Libe R, Perlemoine K, Rene-Corail F, Burnichon N, Gimenez-Roqueplo AP, Dupasquier-Fediaevsky L, Bertagna X, Clauser E, Chanson P et al. Germline inactivating mutations of the aryl hydrocarbon receptor-interacting protein gene in a large cohort of sporadic acromegaly: mutations are found in a subset of young patients with macroadenomas. European Journal of Endocrinology 2007157 1-8. (doi:10.1530/EJE-07-0181)

26 DiGiovanni R, Serra S, Ezzat S \& Asa SL. AIP mutations are not identified in patients with sporadic pituitary adenomas. Endocrine Pathology 200718 76-78. (doi:10.1007/s12022007-0010-z)

27 Cazabat L, Bouligand J \& Chanson P. AIP mutation in pituitary adenomas. New England Journal of Medicine 2011364 1973-1974 (author reply 1974-1975). (doi:10.1056/NEJMc 1101859)

28 Georgitsi M, De Menis E, Cannavo S, Makinen MJ, Tuppurainen K, Pauletto P, Curto L, Weil RJ, Paschke R, Zielinski G et al. Aryl hydrocarbon receptor interacting protein (AIP) gene mutation analysis in children and adolescents with sporadic pituitary adenomas. Clinical Endocrinology 200869 621-627. (doi:10.1111/j.1365-2265.2008.03266.x)

29 Igreja S, Chahal HS, King P, Bolger GB, Srirangalingam U, Guasti L, Chapple JP, Trivellin G, Gueorguiev M, Guegan K et al. Characterization of aryl hydrocarbon receptor interacting protein (AIP) mutations in familial isolated pituitary adenoma families. Human Mutation 201031 950-960. (doi:10.1002/humu.21292)

30 Georgitsi M, Heliovaara E, Paschke R, Kumar AV, Tischkowitz M, Vierimaa O, Salmela P, Sane T, De Menis E, Cannavo S et al. Large genomic deletions in AIP in pituitary adenoma predisposition. Journal of Clinical Endocrinology and Metabolism 200893 4146-4151. (doi:10.1210/jc.2008-1003)

31 Bassett JH, Forbes SA, Pannett AA, Lloyd SE, Christie PT, Wooding C, Harding B, Besser GM, Edwards CR, Monson JP et al. Characterization of mutations in patients with multiple endocrine neoplasia type 1. American Journal of Human Genetics 199862 232-244. (doi:10.1086/301729)

32 Plon SE, Eccles DM, Easton D, Foulkes WD, Genuardi M, Greenblatt MS, Hogervorst FB, Hoogerbrugge N, Spurdle AB, Tavtigian SV et al. Sequence variant classification and reporting: recommendations for improving the interpretation of cancer susceptibility genetic test results. Human Mutation 200829 1282-1291. (doi:10.1002/humu.20880)

33 Occhi G, Trivellin G, Ceccato F, De Lazzari P, Giorgi G, Dematte S, Grimaldi F, Castello R, Davi MV, Arnaldi G et al. Prevalence of AIP mutations in a large series of sporadic Italian acromegalic patients and evaluation of CDKN1B status in acromegalic patients with multiple endocrine neoplasia. European Journal of Endocrinology 2010163 369-376. (doi:10.1530/EJE-10-0327)

34 Jaffrain-Rea ML, Daly AF, Angelini M, Petrossians P, Bours V \& Beckers A. Genetic susceptibility in pituitary adenomas: from pathogenesis to clinical implications. Expert Review of Endocrinology $\mathcal{E}$ Metabolism 20116 195-214. (doi:10.1586/eem.10.87)

35 Korbonits M, Storr H \& Kumar AV. Familial pituitary adenomas who should be tested for AIP mutations? Clinical Endocrinology 201277 351-356. (doi:10.1111/j.1365-2265.2012.04445.x) 
36 Agarwal SK, Kester MB, Debelenko LV, Heppner C, EmmertBuck MR, Skarulis MC, Doppman JL, Kim YS, Lubensky IA, Zhuang $\mathrm{Z}$ et al. Germline mutations of the MEN1 gene in familial multiple endocrine neoplasia type 1 and related states. Human Molecular Genetics 19976 1169-1175. (doi:10.1093/ $\mathrm{hmg} / 6.7 .1169)$

37 Wautot V, Vercherat C, Lespinasse J, Chambe B, Lenoir GM, Zhang CX, Porchet N, Cordier M, Beroud C \& Calender A. Germline mutation profile of MEN1 in multiple endocrine neoplasia type 1 : search for correlation between phenotype and the functional domains of the MEN1 protein. Human Mutation 200220 35-47. (doi:10.1002/humu.10092)

Received 30 August 2012

Revised version received 11 January 2013

Accepted 15 January 2013 